\title{
A CASE OF CHONDROMA BULBI * $\dagger$
}

\author{
BY
}

\author{
AARNi AJO \\ STOCKHOLM
}

In the very rare circumstances where one comes across cartilaginous tissue in the eye it has either been a question about eyes which have not developed normally or about healthy eyes which have been attacked by some serious, destructive disease.

Michel has published a report about a case ot congenital anophthalmus, where the "eyes," in exceptionally contracted orbits, were formed by cartilaginous nodules the size of a pea, covered by conjunctiva and surrounded by eye muscles. In cases of microphthalmos, cartilaginous tissue has been established by Hess and Dötsch. In Hess's case (it concerned an embryo) the cartilage stretched from the connective-tissue-charged corpus vitreum right up to the anterior chamber. In the case published by Dötsch, the cartilage formation existed slightly below the crystalline lens. In all these cases it was hyaline cartilage.

As said; real cartilaginous tissue has, in isolated cases, even been encountered in a previously healthy and normally developed eye, which, through some destructive disease, more often of a tratmatic nature, has subsequently atrophied (phthisis bulbi). In such cases the cartilage has arisen from an ultimate connective-tissuechanging of an abscess in the corpus vitreum or quite possibly it might have had its origin from the elastic choroid membrane (Greeff).

It sometimes happens that hyaline cartilage occurs in mixed tumours of the lacrimal gland. This would account for the fact that these tumours are sometimes described as chondroma proper (Seidal).

Two cases of chondroma in the eyelid have, to my knowledge, been published. The first was described by E. Fuchs in 1878. It concerned a pea-sized hard tumour, attached to the tarsus and consisting of broad united homogeneous fibres. The structure of the tumour differed from that of an ordinary tarsus only by the width and rigidity of the fibres. As Fuchs himself admits, the tumour described can scarcely be regarded as a true chondroma.

The second case was described by Keyser at a congress of American Ophthalmologists in Maryland in 1895. Seven years previously Keyser had extirpated a hard cartilaginoid swelling from the

* From the Ophthalmic Department (at that time under the charge of Dr. A. Ajo, M.D.), of the Central Military Hospital in Helsingfors (at that time in the charge of Dr. L. J. Ollonquist) and the Pathological Department of the Karolinska Hospital in Stockholm, Sweden (Chief: Professor Polke Henschen, M.D.).

+ Received for publication, March 7, 1946. 
lower eyelid of a woman. The tumour had developed during the period of one year, and proved to be adherent to the tarsus. Two years after the operation the swelling recurred and was again removed. After a further two years Keyser, on account of a fresh recurrence, was compelled to extirpate the whole tarsus together with part of the conjunctiva. A microscopic examination showed that the tumour was a chondroma.

From all accounts the occurrence of cartilaginous tissue as a real tumour or even as a part of a mixed tumour in an otherwise sound eye seems to be very rare. At all events I have not come across anything similar in the literature. Therefore I consider it justifiable to give an account of my own observations of a case of chondroma bulbi, despite the fact that the case in question could never be fully investigated.

The patient is a 19-year-old sailor from Pargas (Finland). No hereditary tendencies. He has always been in good health with the exception of two attacks of angina. Vision in the left eye has been poor since birth. As long as the patient can remember he has always had two tumour formations in the conjunctiva of the eye and two grey; opaque spots in the cornea. Nevertheless the eye has been white and completely without irritation whilst the vision has remained the same until two years ago. Then the eye began to ache and redden, show signs of photophobia and, in this connection, the vision became poorer whilst the swellings became enlarged. Later the eye was red and watery at times. The patient has not previously sought medical advice, but is now sent to the ophthalmic department of the Military Hospital. Status: Right eye healthy, vision 1.0.

Left eye: vision, finger counting at $25 \mathrm{~cm}$, glasses do not help. In the subconjunctiva of the bulb there are two soft, movable tumours, apparently covered with normal conjunctiva. The one, smaller tumour, 8 o'clock, the other, larger, 11.30 to 4 o'clock. The latter, the thickness and shape of which resemble a thin earth-worm with thinner and thicker sections, stretches upwards and temporally as far as the upper fornix under which it disappears. Both tumours appear to continue over the limbus and grow infiltratively into the corneal parenchyma. The nasal tumour's continuation is reminiscent of the advancement of rheumatic scleritis in the cornea like a deep wedge-shaped opacity. The temporal swelling, with its sharp and straight demarcation line and its slight protuberance from the surface of the cornea looks as if one had covered the lateral part of the cornea by means of a conjunctival flap (Fig. 1). That part of the cornea which is not infiltrated by the tumours, owes its opacity to the many newly-formed deep blood-vessels which grow out from the upper nasal limbus and stretch right up to the nasal demarcation line of the temporal tumour. The corneal epithelium is completely undamaged. The pupil, of which only the lower nasal part is visible, reacts normally. No changes are noticeable in the fundus of the eye. Pressure normal. No motility disturbances. E.S.R. $2 \mathrm{~mm}$., Wassermann reaction negative.

The patient, who, on account of his sure and concise answers, appears to be keen and of sound judgment, has in his left eye either a congenital tumour or one which developed in his early infancy. These are probably two different tumours

The clinical picture of the tumour with its infiltrative growth in the corneal parenchyma suggests, to a certain extent, malignancy. In sharp contrast to this, however, is the anamnetic information given by the patient. According to this, both the swellings in the conjunctiva as well as the spots in the cornea have remained unchanged in size and shape until the age of 17 years. Therefore the 


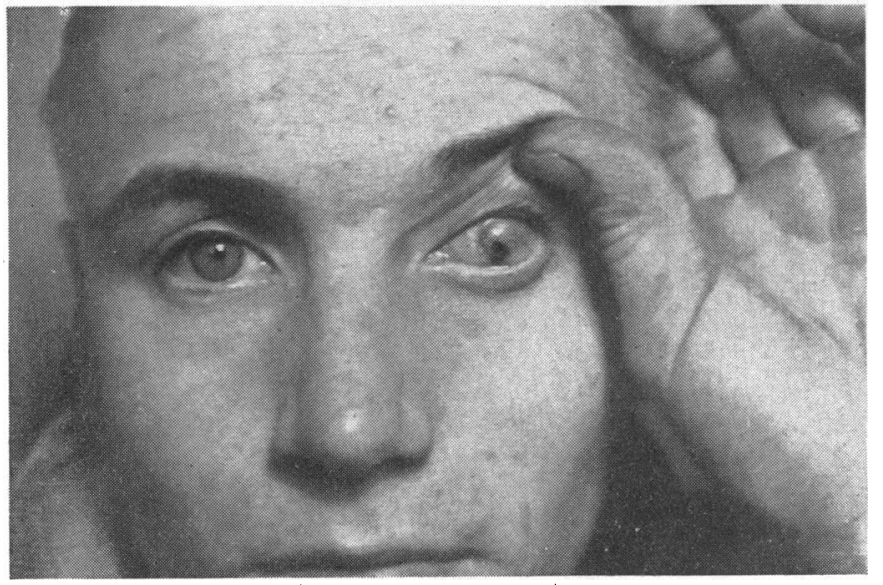

FIG. 1.

The patient during his first visit.

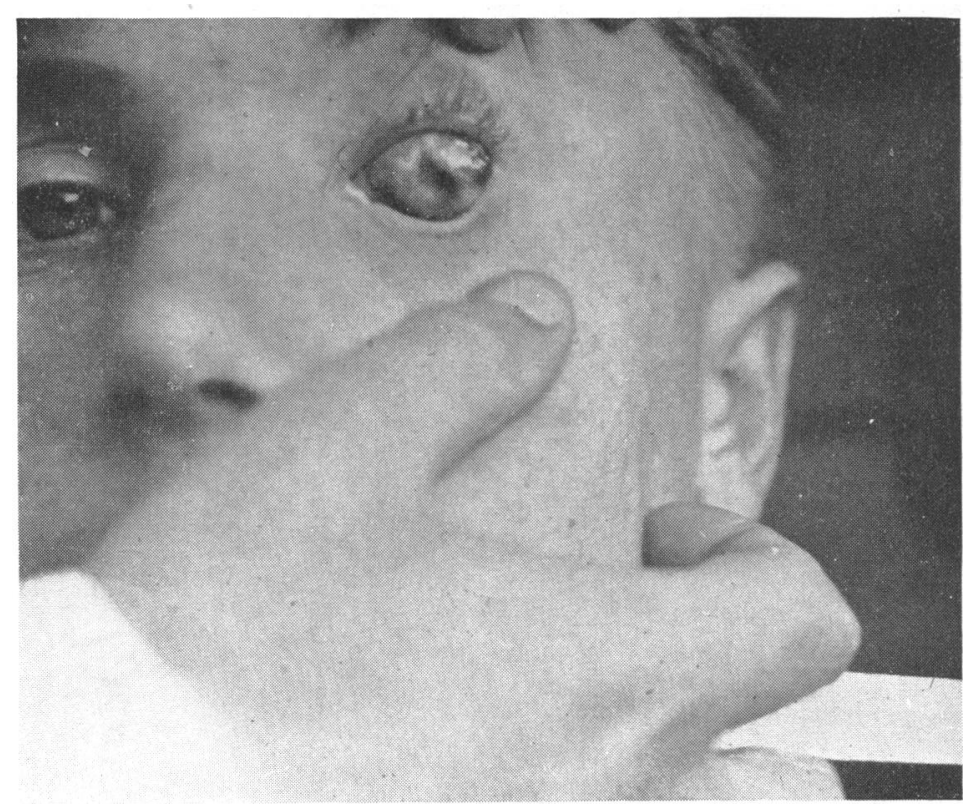

FIG. 2.

The patient one year later. 
A section through the excised tissue. Above lacrimal gland tissue, below cartilaginous tissue. To the left a small island of cartilage. (Magnitying-glass enlargement). 
Section from the border between lacrimal gland and the chondroma. (Medium enlargement).

FIG. 4. 


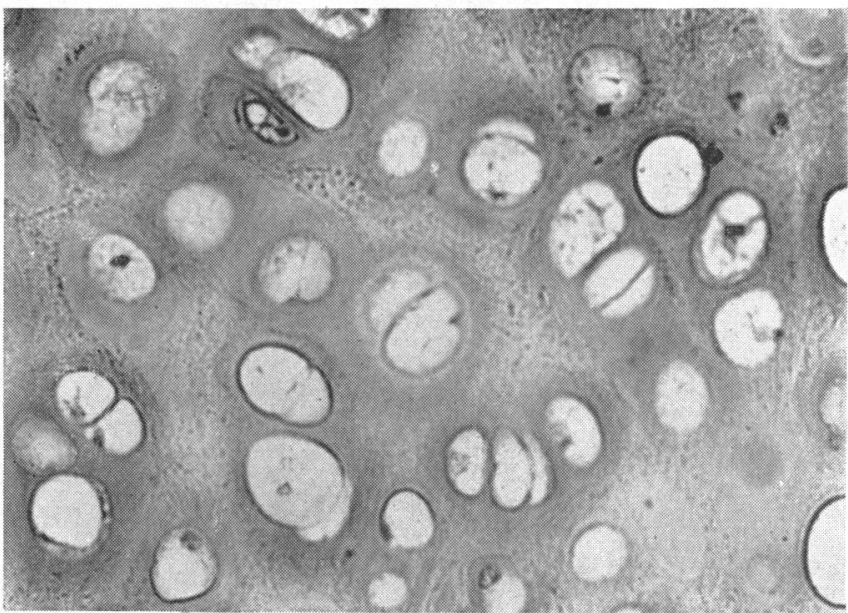

FIG. 5.

Section from the interior of the chondroma. Typical hyaline cartilage tissue. (Greáter enlargement).

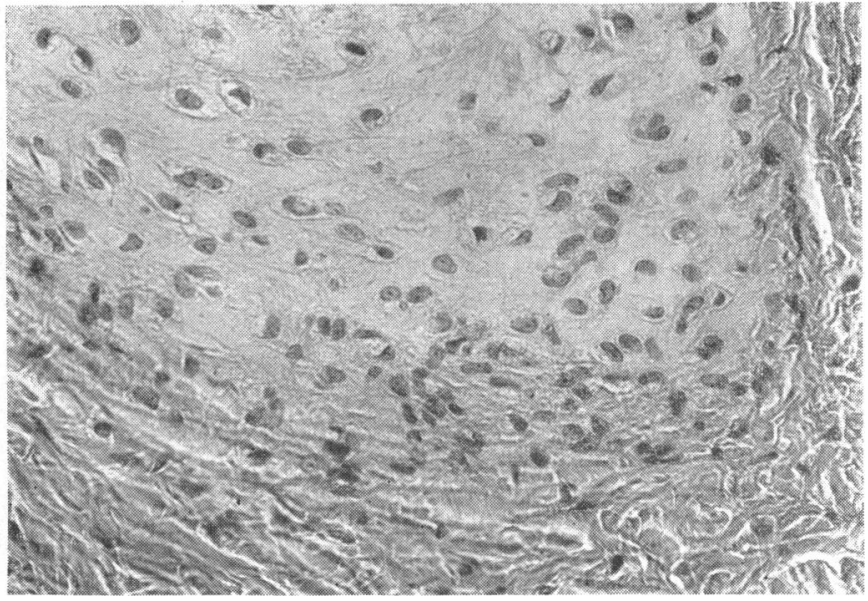

FIG. 6.

Section from the periphery of the chondroma transforming into connective tissue stroma. Cellular, not very differentiated tissue.' (Enlargement same as Fig. 5). 
growth of the tumour should have ceased either before birth or soon after. It coincides that the eye was completely free from irritation and white until two years ago when it began to ache, redden and became photophobic, in other words the eye became inflamed. At the same time the sight became weaker.

The deep blood-vessels in the cornea confirm the fact that the inflammation in question at least attacked the cornea. In the deeper parts of the eye, as far as it was possible to inspect them, there were no signs of any sustained inflammation such as, for instance, posterior synechia or such-like.

$\mathrm{W}^{\top}$ as the tumour the cause of this deep keratitis, has it directly or indirectly caused the origin of the keratitis, or has the corneal inflammation merely been an incidental disease sui generis? The question seems rather difficult to answer.

With regard to the weakening sight noticed by the patient, it can be fully presupposed by, and have sufficient explanation in, the pannus-formation with its numerous, closely placed bloodvessels. It is therefore nut possible to draw any conclusions regarding the expansion of the tumour on the basis of the wrakening of the sight. Further, the growth of the conjunctival swellings alleged by the patient, can perhaps have its natural explanation in the inflammation in the surrounding conjunctiva in connection with the keratitis, and with the concomitant thickening of it.

In order to obtain a diagnosis, an exploratory excision of the tumour was undertaken. In this connection the larger, temporal swelling was extirpated almost in its entirety. The operation was easy to perform as the tumour was not adherent either to the conjunctiva or the sclera but lay freely movable in the subconjunctiva. It was only at the limbus that it had grown together with the surroundings and seemed to continue without a break right into the corneal parenchyma, growing under the limbal conjunctiva and the corneal epithelium.

The morbid histology diagnosis was : chondroma without signs of malignancy (Professor H. Castrén).

Microscopic examination: A section through the excised tissue shows lacrimal gland tissue and cartilaginous tissue (Fig. 3). The lacrimal gland tissue is outwardly surrounded by a loose connective tissue capsule which seems to be a natural boundary to another tissue and not a part of a connective tissue septum on the other side of which further lacrimal gland tissue could be expected. The gland is divided in half by a septum of adipose tissue.

The cartilaginous tissue consists of a larger irregular part, the size of which cannot be judged when it is very reduced by a section laid after the fixation but before the embedding, and a small oval part which in accessible sections lacks connection with the bigger part. The cartilaginous tissue is separated from the lacrimal gland tissue by means of loose connective tissue and a thin connective tissue capsule (Fig. 4) but is, on the other hand to a large extent as if embedded in or surrounded by the same. It consists of typical hyaline cartilage (Fig. 5) which is richer in cells in the periphery and less differentiated. and rapidly passes over to collagenic connective tissue (Fig. 6). No polymorphism, no mitosis, no signs of malignancy. Nowhere are there any epithelial structures as in the majority of tumours of the salivary or the mucous glands. 
The tumour thus shows itself to be a case of a pure chondroma without signs of malignancy. The question then arises: From where can the tumour be thought to originate, which is its mother tissue? The close topographical connection with the lacrimal gland tissue leads one immediately to think that it is a chondroma emanating from this. Similar tumours are, according to Seidel, described as being in the Tacrimal gland, but if it really has been a question of pure chondromata and not a matter of cartilaginous mixed tumours, is uncertain. If, on the other hand, one goes to the salivary or mucous tumours of the mouth which in so many respects resemble those of the lacrimal gland, one will find there definite true chondromata described. Therefore there is nothing to prevent one from regarding the tumour as a chondroma of the lacrimal gland.

On the other hand it is quite clear that the tissue of the lacrimal gland which is encountered presents an extraordinary localisation far out from the real environment of the lacrimal gland. It is, however, known that lacrimal gland tissue in rare cases can appear in the conjunctiva and even in the cornea. A similar instance of heterotopic lacrimal gland has been described by Heuven. It is most probable that a similar aberrant lacrimal gland has been the cause of the chondroma.

Hereby naturally the question of the chondroma matrix has not been definitely decided, since even the subconjunctival connective tissue and the corneal stroma may have been the real source from which the tumour can be considered to have grown into the tissue of the lacrimal gland. Complete clarity on this point cannot be reached without an examination of the whole eye which, hitherto, has not been possible.

Now if the tumour is a chondroma without signs of malignancy; how does this coincide with the opacities in the cornea? Can they be considered as a result of the keratitis or can they be considered as being the continuation of the chondroma in the cornea?

The following facts speak for the first named possibility : first, according to the patient's history, the eye has been inflamed, and second, the deep blood-vessels in the cornea give evidence that the cornea has been attacked.

For the latter possibility we have: first the morbid histological diagnosis, secondly the observations made during the operation on the continuation of the tumour in the corneal parenchyma, and thirdly the protuberance of the temporal opacity on the surface of the cornea.

It therefore seems probable that the corneal opacities are produced by the radiation of the chondroma in the cornea. But the infiltrative growth of the tumour in the corneal parenchyma is in conflict with its innocency. 
Has the tumour ceased to grow, and why, or had it only temporarily done it during early childhood and then actually begun to grow again as the patient stated? From where does the tumour originate? What is the cause of the keratitis?

All these questions must remain unanswered.

It is to be regretted that the patient, despite his poor sight and the unsightliness of the eye, was unwilling to undergo an enucleation as this would have been the only way in which the case could have been fully cleared up. As it concerned a seeing eye in which there was no trace of malignancy there was no justification in trying to persuade him to submit to a mutilating operation.

The patient came again a year later. In the meantime, he said, the eye had ached at times and the sight had become poorer as a result of the continued growth of the tumour.

An examination of the eye caused one immediately to notice that the tumour had grown indeed. The cornea was surrounded on all sides by grey new growth which infiltrated the cornea elevating it from its surface as will be seen from Fig. 2. The remaining free part of the cornea was, as before, clouded with deep bloodvessels although not in a higher degree than that part of the pupil could still be seen. Poor red reflex but no penetration. Vision finger-counting at $20 \mathrm{~cm}$. (V. o. dx 1.0).

Consequently the tumour had grown considerably during the course of one year and the manner of growth was malignant.

The patient's earlier information that the swellings in the eye had begun to grow three years ago seems therefore to have been correct.

Even though the disease had so manifestly progressed and the eye, from a cosmetic point of view, not fulfilled the smallest demands, the patient even now would not submit to an enucleation. He was therefore transferred to the Roentgen department for treatment and his ultimate fate is unknown to me.

I take this opportunity of expressing my most grateful thanks to Prof. Folke Henschen for his kindness in allowing me to carry out the microphotography of my preparations (worked out in the Pathological Institute in Helsingfors) in his institute and for his valuable opinion concerning them.

\section{BIBLIIOGRAPHY}

Dörsch, A.-Anatomische Untersuchungen eines Falles von Mikrophthalmus ccngenitus bilateralis. Gr. Arch. f.|Augenheitk., 1899:48, $1: 59$.

Fucrs, E.-Uber das Chalazion und über einige seltenere Lidgeschwülste. Gr. Arch.f. Augenheilk., 1878:24, 2:121.

GREEFF, R.-Handb. d. spez. path. Anat. u. Histol. (Henke-Lubarsch), Berlin. Vol: XI, p. 1, 1928.

Hess, C.-Zur Pathogenese des Mikrophthalmus. Gr. Arch. f. Augenheilk.. $1888: 34,3: 147$. 
Heuven, V.-Dislocatio glandulae lacrimalis. Nederl. Tijdschr. Geneesk. 1928, II : 3566 . Ref. Seidel.

KEYSER.-Un cas d'enchondrome du tarse de la paupiére supérieure. Ann. d'Ocul. $1895: 69,114$.

Michel, J.-Ein Fall von Anophthalmus Bilateralis. Gr. Arch. $f$. Augenheilk., $1878: 24,2: 71$.

Seidel, E.-Handb. d. spez. path. Anat. u. Histol. Henke-Lubarsch), Berlin. Vol. XI, p. 2. 1931.

\section{THE DIAGNOSTIC AND CLINICAL VALUE OF SOME FORMS OF RETINAL ANGIOSPASM*}

BY

N. Pines

LONDON

THE scope of this paper is limited. It will not include spasm of the venous system, rarely seen but undoubtedly existing (it is frequently seen on the arms, when making an intravenous injection). And the chief interest, if any, of this paper is the connection it tries to establish between the ophthalmoscopic picture of the retina and the result of the general clinical examination, especially that of the arterial circulation. As far as bibliography is concerned, the writer thought it amply sufficient to refer only to two such monumental works on the subject as Bailliart's " Circulation Retinienne" and the Text-book of Ophthalmology by Sir Stewart Duke-Elder. The ophthalmoscope was the same old oneWolf's, with a red-free filter of green glass, with a 12 volt bulb, working to a maximum and to a short-life through a rheostat, attached to a carbon-bulb. It is important to achieve a very considerable degree of brilliancy to see clearly many details. Until the technique is mastered, it is advisable to dilate the patient's pupil and to work in a darkened room. This kind of observation puts a good deal of strain on the observer and must be of necessity short. Nor is the patient likely to stand it for a prolonged period, although the brilliancy of the light is mollified for him by the green filter. I did not find the mesh for measurement of the retinal vessels of much use.

\section{Physiological angiospasm}

In a perfectly healthy fundus, so rarely seen, because the translucency of the arterial wall is usually lost in childhood as a result of various infectious diseases, if the observer follows very carefully all the primary, secondary, etc., branches of the arteries, starting from their emerging point on the surface of the disc and scrutinising every bit up to the utmost periphery - the arteries are naturally

\footnotetext{
* Received for publication, August 23, 1945.
} 